\title{
PEMBERIAN TERAPI TERTAWA TERHADAP KLIEN HIPERTENSI UNTUK MENURUNKAN HIPERTENSI DI DESA BLAMBANGAN UMPU KABUPATEN WAYKANAN LAMPUNG
}

DOI: https://doi.org/10.33024/jkpm.v4i4.2856

\author{
Wahid Tri wahyudi $^{1 *}$, Yessi Aprianti ${ }^{2}$, Triyoso $^{3}$ \\ 1,3Program Studi Ilmu Keperawatan Universitas Malahayati
}

Disubmit: 16 Juni 2020 Diterima: 01 Agustus 2021 Diterbitkan: 02 Agustus 2021

Email Korespondensi :nisun.yudi@yahoo.com

\begin{abstract}
ABSTRAK
Penyakit degeneratif merupakan penyakit jantung, hipertensi, diabetes, kegemukan dan lainnya. Salah satu penyakit degeneratif di antaranya hipertensi. Hipertensi adalah suatu penyakit darah tinggi merupakan suatu keadaan peredaran darah meningkat secara terus menerus dimana tekanan sistolik lebih dari $140 \mathrm{mmHg}$, tekanan diastolik $90 \mathrm{mmHg}$. selain itu penyebab tekanan darah meningkat terjadi karena faktor usia, jenis kelamin, merokok, stress, kurang olahraga, genetic, alcohohol, konsentrasi garam dan obesitas. Pengobatan non farmakologis untuk hipertensi yaitu terapi tertawa. Terapi tertawa adalah salah satu terapi untuk mencapai kegembiraan, kesenangan, kebahagiaan, didalam hati yang dikeluarkan melalui mulut dalam bentuk suara tawa, senyuman yang menghiasi wajah, suara hati yang lepas dan bergembira, peredaran darah yang lancar sehingga bisa mencegah penyakit. Adapaun kegiatan yang dilakukan berupa penyuluhan menggunakan leaflet dan SOP pemberian terapi tertawa. Terdapat penurunan Hipertensi setelah dilakukan terapi tertawa pada penderita Hipertensi di Desa Blambangan Umpu. Dengan demikian pemberian terapi tertawa sangat efektif dalam menurunkan Hipertensi.
\end{abstract}

Kata Kunci: Hipertensi, Non Farmakologis, Terapi Tertawa

\section{ABSTRACT}

Degenerative diseases are non communicable diseases, which lasted chronic such as heart disease, hypertension, diabetes, obesity and other. One of degenerative diseases such as hypertension. Hypertension is a disease of high blood pressure is a state of increased blood circulation in which the sistolic pressure is more than $140 \mathrm{mmHg}$, systolic pressure $90 \mathrm{mmHg}$. besides that the cause of increased blood pressure occurs due to factors of age, sex, smoking, stress, lack of exercise, genetic, alcohol, salt concentration and obesity. Non pharmacological treatment for hypertension is laughter therapy. Laughter therapy is a therapy to achieve joy, pleasure, happiness, in the heart that is issued through the mouth in the form of laughter, smiles that decorate the face, loose and happy conscience and blood circulation that can be adapted to disease. As for the activities carried out in the form of counseling using leaflets and SOP providing laughter therapy. There was a decrease in hypertension after laughing was 
carried out in patients with hypertension in Blambangan Umpu village. The administration of laughter therapy is very effective in reducing hypertension

Keywords: Hypertension, Non Farmacology, Laughter Therapy

\section{PENDAHULUAN}

Penyakit tidak menular (PTM) seperti penyakit kardiovaskuler, kanker, diabetes, dan penyakit paru kronis telah menggantikan penyakit infeksi sebagai penyebab terbanyak kematian di seluruh dunia. World Health Organization (WHO) memperkirakan pada tahun 2020 PTM akan menyebabkan $73 \%$ kematian dan $60 \%$ seluruh kesakitan didunia. Negara yang paling merasakan dampaknya adalah negara berkembang termasuk Indonesia. Menurut World Health Organization diseluruh dunia, sekitar 972 juta orang atau $26,4 \%$ penghuni bumi mengidap hipertensi. Hipertensi merupakan salah satu PTM yang menjadi masalah kesehatan yang serius, hipertensi disebut sebagai "the silent killer" WHO (dalam Yonata dkk, 2016).

Penyakit tidak menular (PTM) merupakan penyebab kematian hampir 70\% didunia. PTM diantaranya adalah penyakit jantung, stroke, kanker, diabetes, PPOK dan hipertensi. Secara nasional prevalensi penduduk dengan hipertensi sebesar $34,11 \%$. Hipertensi pada perempuan lebih tinggi dari pada laki-laki yaitu 36,85\% sedangkan laki-laki 31,34\%. Pada daerah perkotaan sedikit lebih tinggi yaitu 34,43\% sedangkan didaerah perdesaan sebesar 25,8\% (Kementrian Kesehatan RI, 2018).

Hipertensi merupakan suatu keadaan yang menyebabkan tekanan darah tinggi secara terus menerus dimana tekanan sistolik lebih dari 140 $\mathrm{mmHg}$, tekanan diastolik $90 \mathrm{mmHg}$ atau lebih. Hipertensi atau penyakit darah tinggi merupakan suatu keadaan peredaran darah meningkat secara kronis. Hal ini terjadi karena jantung bekerja lebih cepat memompa darah untuk memenuhi kebutuhan oksigen dan nutrisi didalam tubuh (Koes Irianto, 2014). Tekanan darah tinggi merupakan penyakit degeneratif yang banyak diderita bukan hanya oleh usia lanjut bahkan saat ini juga menyerang orang dewasa muda. Komplikasi yang mungkin timbul dari hipertensi yaitu penyakit gagal jantung, stroke dan penyakit koroner. Untuk menghindari terjadi komplikasi pada penderita hipertensi, perlu adanya pengontrolan tekanan darah dan perubahan perilaku gaya hidup (Atika, 2016).

Adapun cara penanganan untuk mengatasi hipertensi bisa dilakukan dengan cara nonfarmakologi. Penanganan nonfarmakologi atau disebut juga dengan modifikasi gaya hidup meliputi berhenti merokok, mengurangi kelebihan berat badan, menghindari alkohol, modifikasi diet, minuman kaya akan kafein, seperti kopi dan teh. Penanganan hipertensi nonfarmalogi selanjutnya mencakup psikis antara lain mengurangi stres, olahraga, terapi musik, terapi tawa dan istirahat. Dari beberapa jenis penanganan hipertensi nonfarmakologi salah satu yang saat ini mulai menjadi trend dilakukan adalah terapi tertawa Kataria 2012 (dalam Lase, 2019).

Terapi tertawa merupakan suatu terapi untuk mencapai kegembiraan di dalam hati yang dikeluarkan melalui mulut dalam bentuk suara tawa, atau senyuman yang menghias wajahnya, perasaan hati yang lepas dan bergembira, dada yang lapang, peredaran darah yang lancar, yang bisa mencegah penyakit dan memelihara kesehatan (Arminda, 2020). Tertawa 510 menit bisa merangsang pengeluaran endorphin dan serotonin, yaitu sejenis morfin alami tubuh dan juga melatonin. Ketiga zat ini merupakan zat yang 
baik untuk otak sehingga kita bisa merasa lebih tenang dan terapi tertawa merupakan tehnik yang mudah dilakukan Padila (2013) dalam Okmalasari (2018).

Hasil penelitian ini sesuai dengan penelitian sebelumnya yang dilakukan Ratnasari dkk (2018) tentang Efektifitas Pemberian Terapi Tertawa Dalam Menurunkan Tekanan Darah Pada Pasien Hipertensi Di Wilayah Kerja Puskesmas Jagong Kecamatan Pangkajane Kabupaten Pangkep, menunjukkan hasil penelitian dapat dilihat bahwa rata-rata tekanan darah sebelum dilakukan intervensi 124.29 didapatkan $p$-value 0.017 dan setelah dilakukan intervensi 124.29 dengan $p$-value 0.038 atau $p<0,05$ berarti ada pengaruh pemberian terapi tertawa terhadap penurunan tekanan darah

Berdasarkan latar belakang tersebut, penulis tertarik untuk melakukan studi kasus "Asuhan Keperawatan Komprehensif Pada Klien Hipertensi Dengan Menggunakan Terapi Tertawa Di Desa Blambangan Umpu Kabupaten Waykanan Tahun 2020”.

\section{MASALAH}

Alasan saya memilih tempat penyuluhan kesehatan tentang hipertensi dan demontrasi tentang pemberian terapi tertawa di Desa Blambangan Umpu Kabupaten Waykanan ialah karena tetangga saya sendiri memiliki masalah kesehatan hipertensi yang tinggi, dimana tujuan umum dalam kegiatan ini diharapkan pemberian terapi tertawa dapat menurunkan tekanan darah pada klien dengan hipertensi, dan tujuan khusus dalam kegiatan yaitu asuhan keperawatan, telaah jurnal untuk menentukan intervensi, evaluasi hasil aplikasi intervensi, perbandingan hasil intervensi pemberian terapi tertawa.

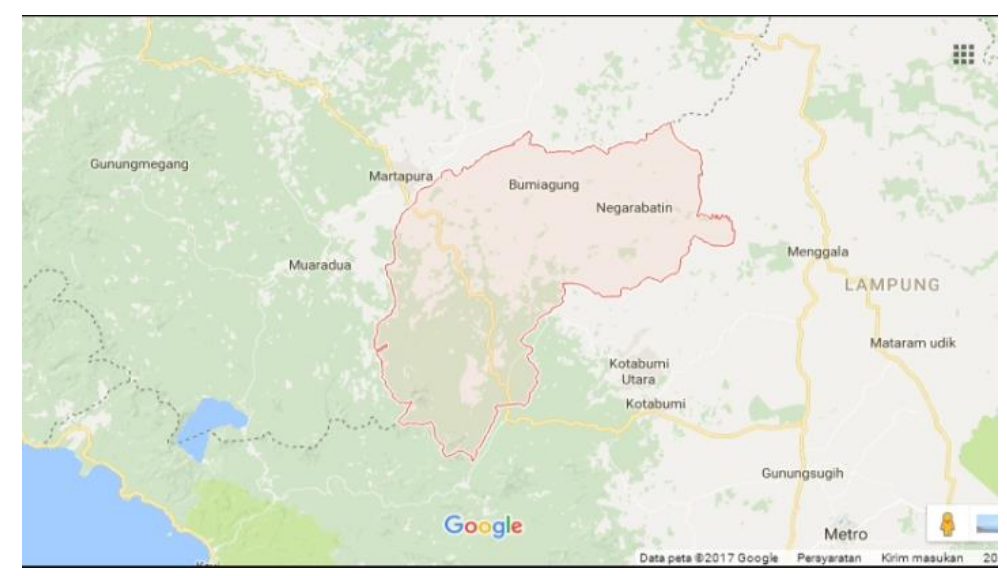

Gambar 2.1 Lokasi penyuluhan dan demonstrasi

\section{METODE}

1. Tujuan Persiapan

Tahap persiapan dari kegiatan adalah pembuatan pre planning, persiapan penyajian leaflet dan demonstrasi, tempat dan alat-alat lainnya disiapkan oleh peneliti. Pembuatan leaflet dibuat pada hari kamis 30 April 2020, pada tanggal 02 Juni 2020 dilakukan penyuluhan, pengecekan tekanan darah, dan demonstrasi pemberian terapi tertawa. 
2. Tahap Pelaksanaan

Kegiatan ini dengan pemberitahuan kepada klien, dilanjutkan penyuluhan, pada hari pertama melakukan pre test dengan mengukur tekanan darah dengan menggunakan tensimeter. Kemudian, melaksanaan intervensi pemberian terapi tertawa. Terapi tertawa dilakukan pada pagi hari sebanyak 3 kali selama 7 hari. Kemudian pada hari terakhir melakukan post test dengan mengukur tekanan darah kembali menggunakan tensimeter.

3. Evaluasi

a. Struktur

Klien sebanyak 1 orang yaitu perempuan. Setting tempat sudah sesuai dengan rencana yang dibuat serta alat dan bahan untuk penyuluhan dan mendemonstrasikan pemberian terapi tertawa sudah tersedia dan sudah digunakan sebagaimana mestinya. Peran peneliti sudah sesuai dengan tugasnya, baik sebagai penanggung jawab, observator, fasilisator, dan dokumentasi. Penggunaan bahasa yang dipraktikkan sudah komunikatif dalam penyampaianya, klien dapat memahami apa yang sudah disampaikan dan dapat mempraktikkan kembali yang sudah didemonstrasikan.

b. Proses

Pelaksanaan kegiatan terapi tertawa dimulai pada hari Sabtu 2 Mei 2020 selama 7 hari pada pukul 10:00 s/d 10:30.

\section{HASIL DAN PEMBAHASAN}

Metode pelaksanaan pemberian terapi tertawa dilaksanakan pada tanggal 02 Mei 2020 s/d 07 Mei 2020. Penelitian dilakukan selama 7 hari, setelah dilakukan pemberian terapi tertawa selama 7 hari didapatkan tekanan darah klien menurun. Berikut pelaksanaan penyuluhan, pengukuran tekanan darah dan pemberian terapi tertawa:
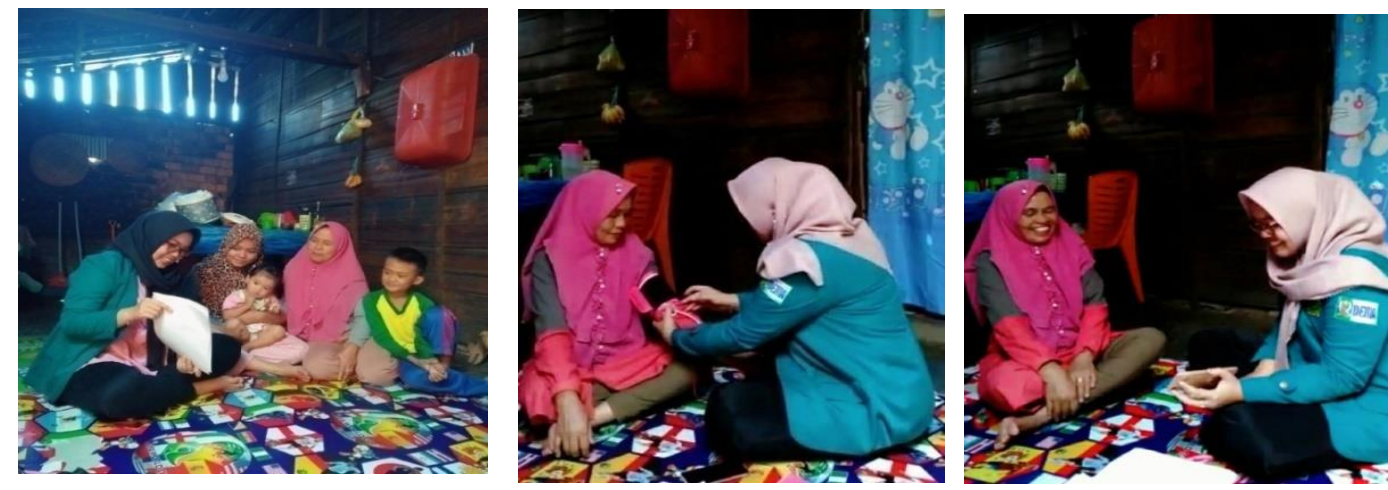

Gambar 4.1 pelaksanaan penyuluhan, pengukuran tekanan darah, dan pemberian terapi tertawa

1. Hasil

Tabel 4.1 Hipertensi Sebelum dan Sesudah Pemberian Terapi

\begin{tabular}{lcc}
\hline Pemberian Terapi Tertawa & Pretest & Posttes \\
& $150 / 100 \mathrm{mmHg}$ & $135 / 95 \mathrm{mmHg}$ \\
\hline
\end{tabular}




\section{Pembahasan}

Berdasarkan Tabel 4.1 menunjukkan hasil evaluasi pada klien, dimana klien mengalami penurunan hipertensi setelah dilakukan pemberian terapi tertawa selama 7 hari, dilakukan 3 kali pada pagi hari. Diperoleh tekanan darah sebelum diberikan terapi tertawa (pretest) yaitu 150/100 mmHg dan tekanan darah setelah diberikan terapi tertawa (posttest) yaitu 135/95 mmHg.

Berdasarkan hasil penelitian sebelumnya yang dilakukan Ratnasari, Kasmawati, Musdalipa \& Azwar (2018) tentang Efektifitas Pemberian Terapi Tertawa Dalam Menurunkan Tekanan Darah Pada Pasien Hipertensi Di Wilayah Kerja Puskesmas Jagong Kecamatan Pangkajane Kabupaten Pangkep, menunjukkan hasil penelitian dapat dilihat bahwa rata-rata tekanan darah sebelum dilakukan intervensi 124.29 didapatkan $\mathrm{p}$-value 0.017 dan setelah dilakukan intervensi 124.29 dengan $\mathrm{p}$-value 0.038 atau $\mathrm{p}<0,05$ berarti ada pengaruh pemberian terapi tertawa terhadap penurunan tekanan darah.

Hipertensi merupakan suatu keadaan yang menyebabkan tekanan darah tinggi secara terus menerus dimana tekanan sistolik lebih dari 140 $\mathrm{mmHg}$, tekanan diastolik $90 \mathrm{mmHg}$ atau lebih. Hipertensi atau penyakit darah tinggi merupakan suatu keadaan peredaran darah meningkat secara kronis. Hal ini terjadi karena jantung bekerja lebih cepat memompa darah untuk memenuhi kebutuhan oksigen dan nutrisi didalam tubuh (Koes Irianto, 2014).

Faktor penyebab hipertensi terbagi hipertensi primer dan sekunder. Genetic dan ras merupakan bagian yang menjadi penyebab timbulnya hipertensi primer, termasuk factor lain yang diantaranya adalah faktor stress, intake alkohol, merokok, lingkungan, demografi dan gaya hidup. Penyebab utama penyakit hipertensi sekunder adalah gangguan yang berhubungan dengan kelainan ginjal dan system endokrin. Gangguan ginjal dapat disebabkan karena penyakit parenkim ginjal (glomerulonefritis, polycystic kidney disease), maupun penyakit ginjal vascular (Triyanto, 2014)

Terapi tertawa merupakan tertawa yang dapat menurunkan tekanan mulai dengan tahap demi tahap. Sehingga efek yang dirasakan bagi yang tertawa benar-benar bermanfaat. Terapi tertawa untuk mengurangi stress sudah banyak dilakukan orang. Tertawa 5-10 menit bisa merangsang pengeluaran endorphin dan serotonin, yaitu sejenis morfin alami tubuh dan juga melatonin. Ketiga zat ini merupakan zat yang baik untuk otak sehingga kita bisa merasa lebih tenang dan terapi tertawa merupakan tehnik yang mudah dilakukan Padila (2013) dalam Okmalasari (2018).

\section{KESIMPULAN}

Saat dilakukan pengkajian pada klien ditemukan data yang sesuai dengan tinjauan teori untuk masalah hipertensi pada klien. Berdasarkan data yang diperoleh, peneliti mendapatkan diagnosa keperawatan yang harus ditangani yang akan dijadikan suatu masalah. Pada intervensi keperawatan yang dilakukan pada klien yaitu sesuai dengan diagnosa keperawatan dan dilakukan pemberian terapi tertawa. Implementasi Keperawatan yang dilakukan berdasarkan pada intervensi yang telah direncanakan. Implementasi dengan pemberian terapi tertawa sebanyak 3 kali selama 7 
hari, pada pagi hari. Setelah dilakukan asuhan keperawatan dan pemberian terapi tertawa selama 7 hari, didapatkan hasil tekanan darah sebelum diberikan terapi tertawa (pretest) yaitu $150 / 100 \mathrm{mmHg}$ dan tekanan darah setelah diberikan terapi tertawa (posttest) yaitu 135/95 mmHg.

Pelaksanaan keperawatan ini memiliki kekurangan dan kelebihan, salah satu kelebihannya adalah pemberian terapi tertawa dilakukan pada saat bulan puasa, sehingga tidak ada hambatan untuk melakukan pemberian intervensi karena bisa dilakukan pada pagi hari. Kekurangan pada penelitian ini adalah pendekatan penulis terhadap klien sedikit kurang terlihat klien tidak rileks, tegang dan sedikit susah untuk tertawa, klien bisa tertawa spontan setelah diberikan oleh penulis video yang lucu. Sehingga menyebabkan penurunan tekanan darah tidak terjadi penurunan secara cepat.

\section{DAFTAR PUSTAKA}

Arminda, F. (2020). Potensi Terapi Tertawa sebagai Terapi Hipertensi. Journal of Health Science AND Physiotherapy, 2

Atika, F. (2016). Hubungan Dukungan Keluarga Dengan Kepatuhan Berobat Pada Pasien Hipertensi Di Puskesmas Tanah Garam Kota Solok Tahun 2016. PhD Thesis. Universitas Andalas

Irianto K. (2014) Epidemiologi Penyakit Menular dan Tidak Menular Panduan Klinis. Bandung: Alfabeta

Kemenkes RI (2018) Penyakit Tidak Menular. Diambil pada 18 April 2020 dari www.depkes.go.id/download.php?file=download/pusdatin/buletin/

Lase, I. P. L. (2019). Pengaruh Terapi Yoga Ketawa Terhadap Penurunan Tekanan Darah Pada Lansia Dengan Hipertensi Di UPT Pelayanan Sosial Lanjut Usia Wilayah Binjai

Okmalasari, F. I., \& Sukesi, N. (2018). Pemberian Terapi Tertawa Untuk Menurunkan Tekanan Darah Pada Pasien Hipertensi Di RSUD KRMT Wongsonegoro Semarang. Jurnal Manajemen Asuhan Keperawatan

Ratnasari, R., Kasmawati, K., Musdalipaa, M., \& Azwar, A. (2018). Efektivitas Pemberian Terapi Tertawa Dalam Menurunkan Tekanan Darah Pada Pasien Hipertensi Di Wilayah Kerja Puskesmas Jagong Kecamatan Pangka Jene Kabupaten Pangkep. BIMIKI (Berkala Ilmiah Mahasiswa Ilmu Keperawatan Indonesia)

Triyanto, Endang. (2014). Pelayanan Keperawatan bagi Penderita Hipertensi secara Terpadu. Yogyakarta: Graha Ilmu

Yonata, A., \& Pratama, A. S. P. (2016). Hipertensi sebagai Faktor Pencetus Terjadinya Stroke. Jurnal Majority. 